\title{
Investigation of the Overvoltages in Electrical Power Lines with a Grounded through a Resistance Neutral
}

\author{
Plamen Stanchev ${ }^{1}$ \\ 1 - Technical University of Varna, Department of Electric Power Engineering, 9010, 1 Studentska Street, Varna, Bulgaria \\ Corresponding author contact: p.stanchev@tu-varna.bg
}

\begin{abstract}
The paper examines the variation of electrical variables during phase-to-ground faults on medium voltage electrical power lines with a grounded through a resistance neutral. The studies were performed with simulation models of a medium voltage electrical power line. The parameters under consideration have been the voltages and the currents in the transient and steady state operation of the line and more precisely their dependence on the variation of the arc resistance in the place of the fault and the distance from the fault to the supply source. Calculated, accordingly, is the overvoltage during the transient process, the maximum magnitude of the overvoltage and phaseto-earth fault current, the duration of the transient phase-to-ground fault current as well as the maximum magnitude of the overvoltage on the neutral.
\end{abstract}

Keywords: power lines, phase to ground faults, medium voltage, overvoltage

\section{Introduction}

In medium voltage (MV) power line, single phase to earth faults are the most common faults. The method of grounding of the neutral of the electric power line medium voltage is determined by many factors, such as (Etarski, 1994, Shabad, 2002, Feldman, 2001, Shalin, 2005, Karafeizov, 2003, MehmedHamza, 2007, Mehmed-Hamza, 2009):

- the magnitude and nature of phase-to-ground currents;

- the overvoltage during phase-to-ground faults;

- the reliable and selective operation of the relay protections;

- values not exceeding the permissible limits for touch and step voltages to the earthing devices for humans and animals;

- limited damages caused by earth faults, etc.

According to the regulation requirements in Bulgaria, the connection of the power source neutral is chosen in relation to the type of network and the magnitude of the earth fault current. Grounding of the neutral is necessary when the capacitive current at phase-to-ground current is greater than $10 \mathrm{~A}$, such as (Ministry of Energy. 2004, Ministry of Energy. 2015):

- for overhead power lines - by means of a reactor or a combination (a reactor and a resistor);

- for cable lines - through a resistor;

- for mixed lines - through a resistor when the cable share is greater than $40 \%$ of the total length of the network and combined (reactor in parallel to resistor) when the cable share is less than $40 \%$.

The paper explores the variation of the electrical variables during single phase-to-ground fault in medium voltage electrical power lines with neutral grounded through a resistor, commensurate with the arc fault resistance and the distance between the fault and the power source.

The investigation was performed within a MATLAB/Simulink-based programming environmentfocusing exclusively ontwo MV electric power lines, namely,. overhead and cable power lines with a total length of $130 \mathrm{~km}$ and cable share of $40 \%$. Standard blocks of the software were thereupon used to construct the relevant models. The rating of the power transformer for the tested medium voltage lines is 40 MVA (Mehmed-Hamza, 2009). Outline in Fig. 1 is the model diagram of the lines under study. 


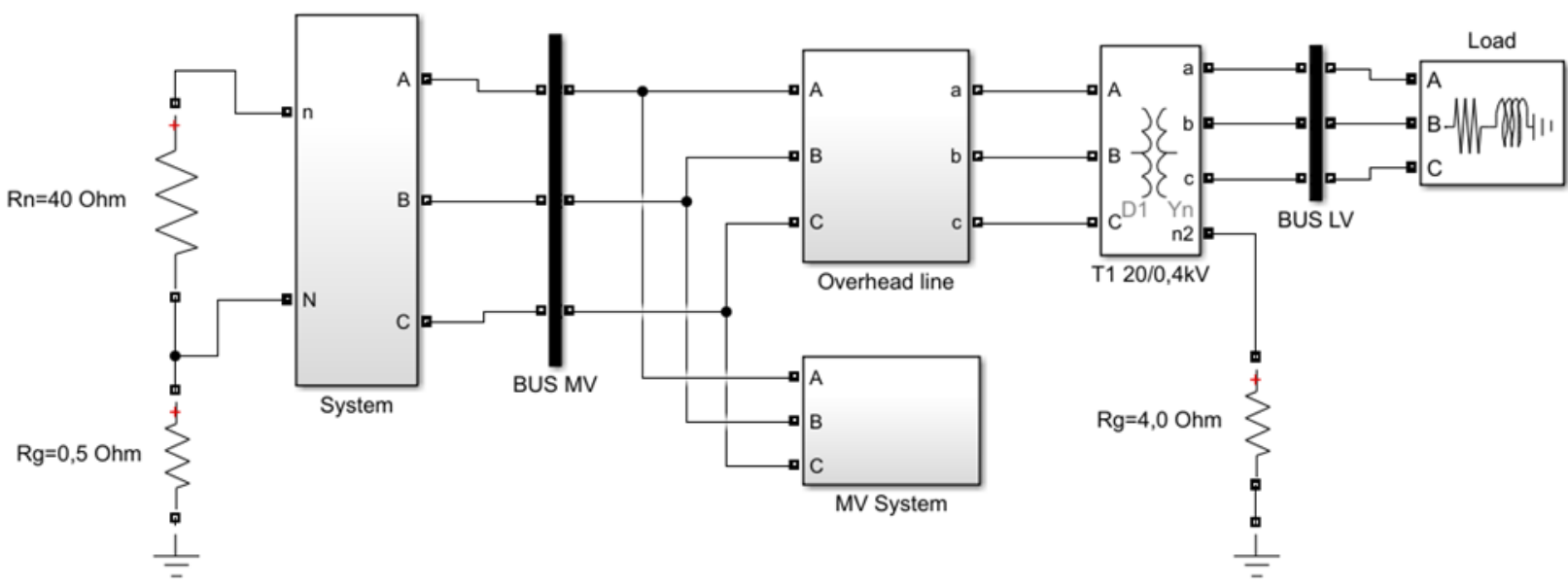

Fig. 1. Model scheme for the studied line

To evaluate the insulation level, the overvoltage $\left(K_{T O V}\right)$ of the undamaged phase conductors during the phase-to-ground transients is calculated in per unit relative to the rated voltage according to (BDS EN IEC 60071-1:2019) as follows:

$$
\begin{aligned}
& K_{\text {TOV }}=\frac{u_{\max }}{19600} \mathrm{p} \cdot \mathrm{u} \\
& 1 \mathrm{p} \cdot \mathrm{u}=19600 \mathrm{~V}
\end{aligned}
$$

where $u_{\text {max }}$ is the maximum measured instantaneous amplitude of the voltage on the undamaged phase conductors, during the transient process of a single phase-to-ground fault.

\section{$2 \quad$ Results and analysis}

Obtained, for the purposes of the studied power lines, are the simulation results for the phase conductors overvoltage, while for the neutral voltage and the single phase-to-ground fault current derived is

- An arc fault resistance $0 \Omega$

- a varying arc fault resistance $0 \Omega$ to $100 \Omega$;

The single phase-to-ground faults were investigated in overhead power lines with ACSR 70 and ACSR 95 conductors for different lengths.

Reported further were the findings for the magnitude of the voltage of the undamaged phases and in the neutral. An analysis was made for:

- the instantaneous maximum measured amplitude of the overvoltages on the undamaged phases conductors and on the neutral

- the maximum $K_{T O V}$ value.

The results for the tested electrical line with $40 \%$ cable share are presented in Tables 1,2 and 3 and Figures 2 to 5 .

Table 1 presents the results for a single phase-to-ground faults at zero arc fault resistance on an overhead power line constructed with ACSR 70 conductor. The failure is simulated at $0,10,20,30$ and $40 \mathrm{~km}$ away from the power source of an overhead line with a length of $40 \mathrm{~km}$.

Conducted aslo were studies into the change in overvoltage dependent on the value of the arc resistance at a single line-to-ground fault. 
Table 1. Results for a single phase-to-ground fault with zero arc resistance on an overhead power line constructed with conductor ACSR 70

\begin{tabular}{|c|c|c|c|c|c|c|}
\hline \multirow{3}{*}{$\begin{array}{l}\text { metal single phase to earth } \\
\text { faults }\end{array}$} & \multicolumn{6}{|c|}{ ACSR 70} \\
\hline & \multirow[b]{2}{*}{$\mathbf{u}_{\text {max,phase, }}, \mathbf{k V}$} & \multicolumn{2}{|c|}{$\mathbf{K}_{\text {TOV,phase }}$} & \multirow[b]{2}{*}{$\mathbf{U}_{\text {max,neutral, }} \mathbf{k V}$} & \multicolumn{2}{|c|}{$\mathbf{K}_{\text {TOV,neutral }}$} \\
\hline & & IEC 60071-1 & $\begin{array}{c}\text { KTov, } \\
\text { Unom }\end{array}$ & & IEC 60071-1 & $\begin{array}{c}\mathbf{K}_{\text {TOV, }} \\
\text { Unom }\end{array}$ \\
\hline $0 \mathrm{~km}$ & 43.042 & 2.20 & 3.73 & 17.338 & 0.885 & 1.502 \\
\hline $10 \mathrm{~km}$ & 36.036 & 1.84 & 3.12 & 13.257 & 0.676 & 1.148 \\
\hline $20 \mathrm{~km}$ & 32.153 & 1.42 & 2.41 & 11.974 & 0.611 & 1.037 \\
\hline $30 \mathrm{~km}$ & 31.703 & 1.62 & 2.75 & 11.084 & 0.565 & 0.960 \\
\hline $40 \mathrm{~km}$ & 30.792 & 1.57 & 2.67 & 10.099 & 0.515 & 0.875 \\
\hline
\end{tabular}

Recorded in Fig. 2 are the results derived for the overvoltage measured on the undamaged phases for a single phase-to-ground fault on an overhead power line and through a varying arc resistance (from $0.001 \Omega$ to $100 \Omega$ ).

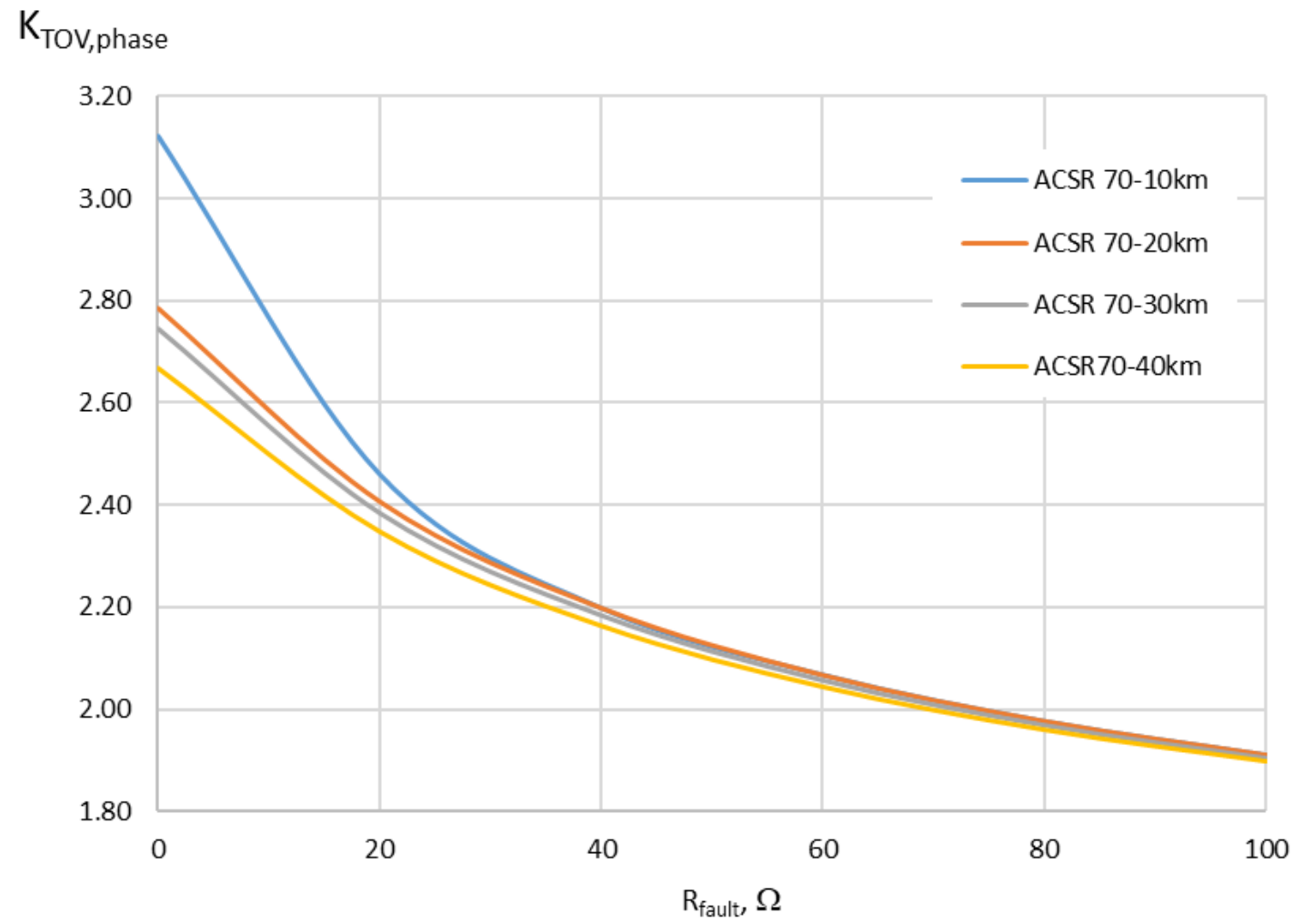

Fig. 2. Overvoltages of the undamaged phases at a single phase to earth faults through an overhead power line and through transient resistance from $0,001 \Omega$ to $100 \Omega$.

Fig. 3 displays the results of the overvoltage measured across the neutral during a single phase-toground fault on an overhead line and through a varying arc resistance (from $0.001 \Omega$ to $100 \Omega$ ). 


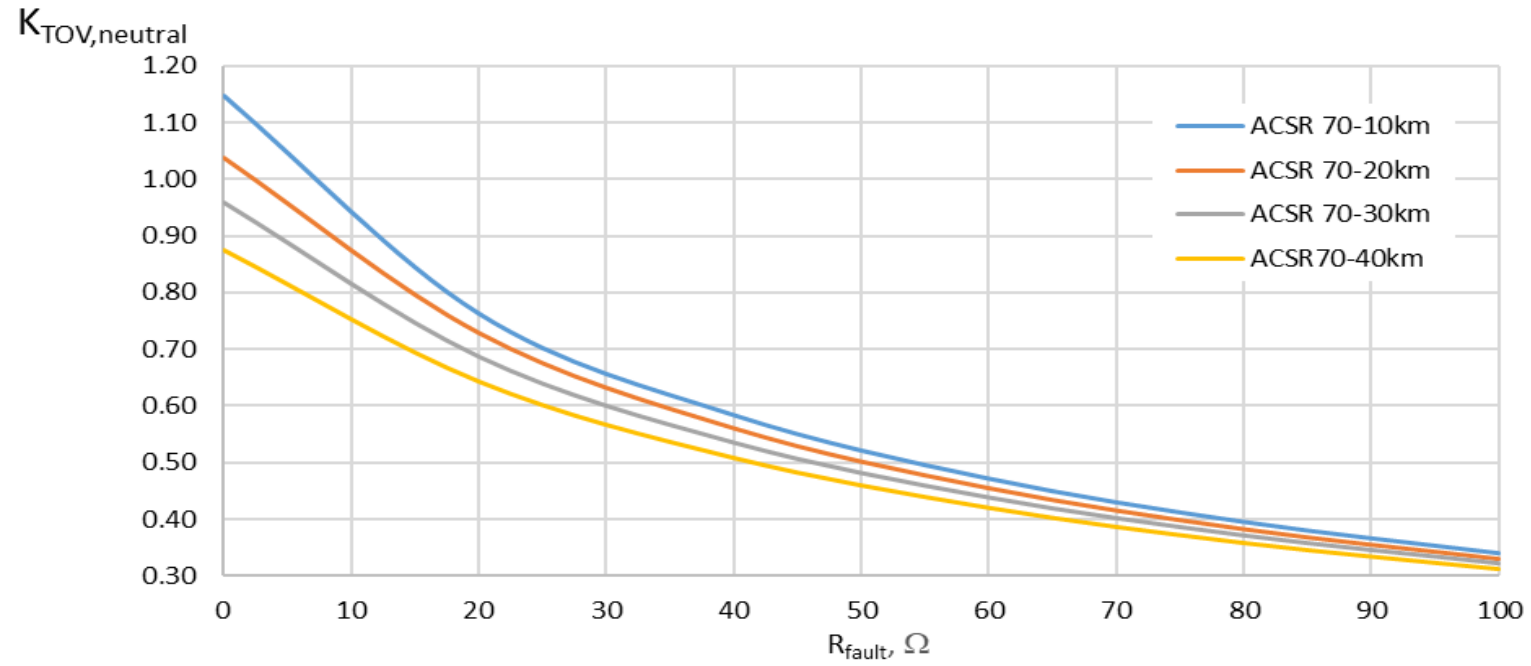

Fig. 3. Overvoltages of the neutral at the single phase to earth faults through an overhead line and through the transient resistance from $0,001 \Omega$ to $100 \Omega$.

The results observed for an overhead line with ACSR 95 conductors are presented in Table 2 and Fig. 4 and 5.

Table 2. Results for a metal single phase to earth faults of an ACSR 95overhead power line

\begin{tabular}{|c|c|c|c|c|c|c|}
\hline \multirow{3}{*}{$\begin{array}{l}\text { Single phase to earth } \\
\text { fault }\end{array}$} & \multicolumn{6}{|c|}{ ACSR 95} \\
\hline & \multirow[b]{2}{*}{ Umax,phase, $\mathbf{k V}$} & \multicolumn{2}{|c|}{ KTOV,phase } & \multirow{2}{*}{$\begin{array}{l}\text { Umax,neutral, } \\
\mathbf{k V}\end{array}$} & \multicolumn{2}{|c|}{ KTOV,phase $_{\text {T }}$} \\
\hline & & IEC 60071-1 & $\begin{array}{c}\mathbf{K}_{\text {TOV, }} \\
\text { Unom }\end{array}$ & & IEC 60071-1 & $\begin{array}{c}\text { KTov, }_{\text {Un }} \\
\text { Un }\end{array}$ \\
\hline $0 \mathrm{~km}$ & 42,97 & 2,19 & 3,72 & 17,31 & 0,88 & 1,50 \\
\hline $10 \mathrm{~km}$ & 36,59 & 1,87 & 3,17 & 13,66 & 0,70 & 1,18 \\
\hline $20 \mathrm{~km}$ & 32,70 & 1,66 & 2,82 & 12,43 & 0,63 & 1,08 \\
\hline $30 \mathrm{~km}$ & 32,51 & 1,66 & 2,82 & 11,70 & 0,60 & 1,01 \\
\hline $40 \mathrm{~km}$ & 31,76 & 1,62 & 2,75 & 10,80 & 0,55 & 0,94 \\
\hline
\end{tabular}

$\mathrm{K}_{\mathrm{TOV}, \text { phase }}$

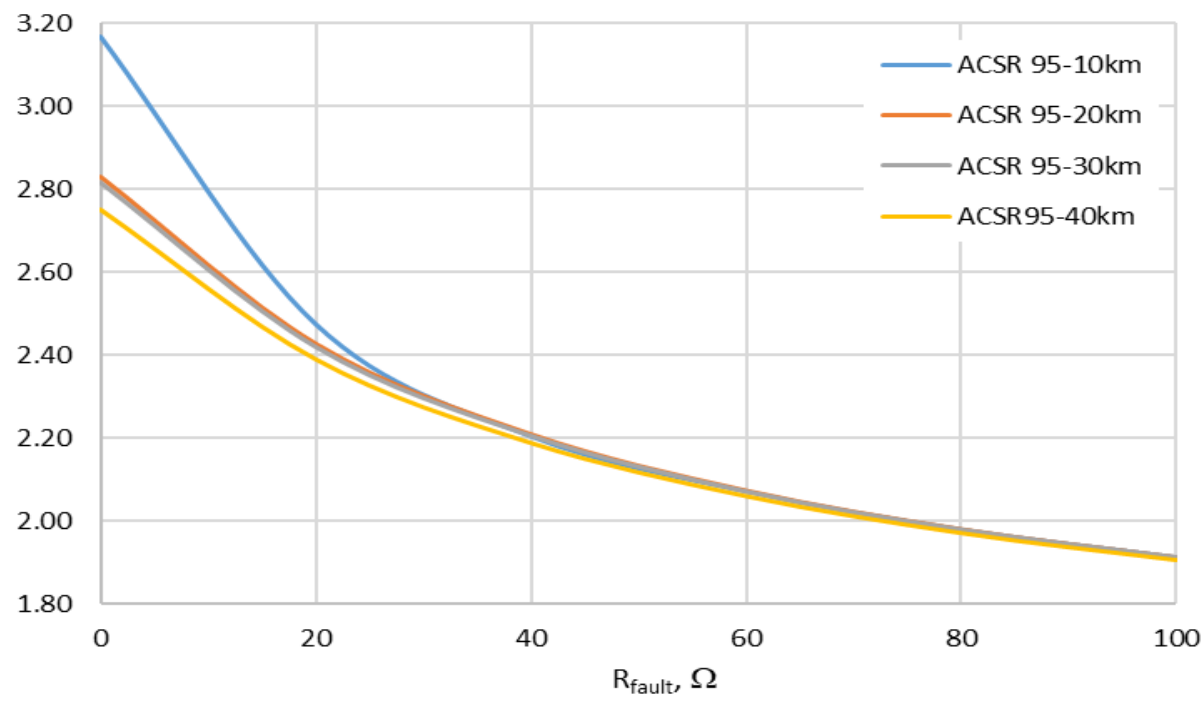

Fig. 4. Overvoltages of the undamaged phases at a single phase to earth faults through an overhead power line and through transient resistance from $0,001 \Omega$ to $100 \Omega$. 


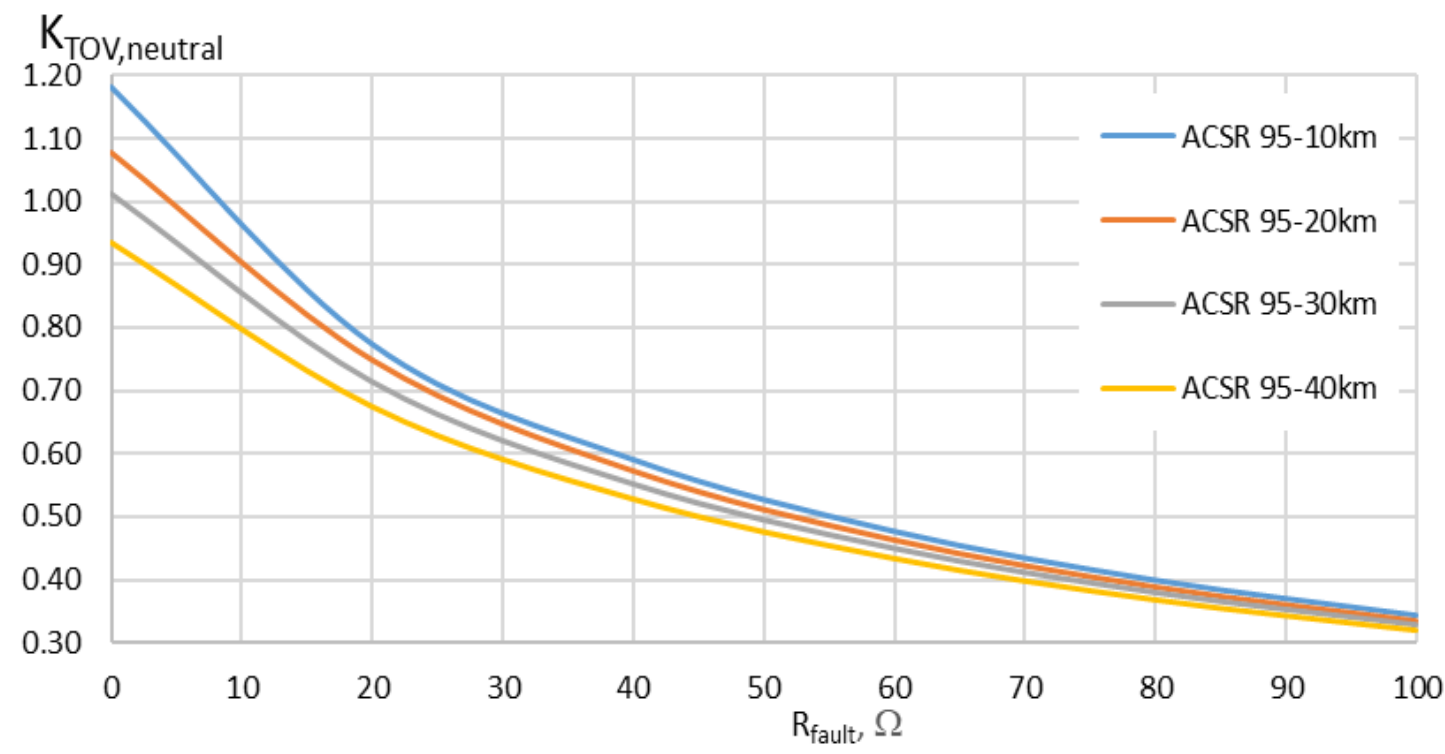

Fig. 5. Overvoltages of the neutral at the single phase to earth faults through an overhead line and through transient resistance from $0,001 \Omega$ to $100 \Omega$.

Arranged in Table 3 are the results of the maximum overvoltage measured on the undamaged phases and calculated in accordance with (BDS EN IEC 60071-1:2019) and conditional upon the arc fault resistance and the fault distance from the source.

Table 3. Overvoltage of the undamaged phases calculated according to (BDS EN IEC 60071-1:2019)

\begin{tabular}{|c|c|c|c|c|c|c|c|}
\hline & Distance & 0,001 & $20 \Omega$ & $40 \Omega$ & $60 \Omega$ & $80 \Omega$ & $100 \Omega$ \\
\hline \multirow{4}{*}{ ACSR 70} & $10 \mathrm{~km}$ & 1,84 & 1,45 & 1,30 & 1,22 & 1,17 & 1,13 \\
\hline & $20 \mathrm{~km}$ & 1,64 & 1,42 & 1,29 & 1,22 & 1,16 & 1,13 \\
\hline & $30 \mathrm{~km}$ & 1,62 & 1,40 & 1,29 & 1,21 & 1,16 & 1,12 \\
\hline & $40 \mathrm{~km}$ & 1,57 & 1,38 & 1,27 & 1,20 & 1,15 & 1,12 \\
\hline \multirow{4}{*}{ ACSR 95} & $10 \mathrm{~km}$ & 1,87 & 1,46 & 1,30 & 1,22 & 1,17 & 1,13 \\
\hline & $20 \mathrm{~km}$ & 1,67 & 1,43 & 1,30 & 1,22 & 1,17 & 1,13 \\
\hline & $30 \mathrm{~km}$ & 1,66 & 1,43 & 1,30 & 1,22 & 1,17 & 1,13 \\
\hline & $40 \mathrm{~km}$ & 1,62 & 1,41 & 1,29 & 1,21 & 1,16 & 1,12 \\
\hline
\end{tabular}

For the investigated electrical grid, the transient overvoltage duration is up to 1 fundamental frequency cycle.

From the findings generated for the tested electrical lines it appears that in the power transformer's neutral grounded with a resistor, the overvoltage consistent with (BDS EN IEC 60071-1:2019) and measured on the undamaged phases tends to decrease, varying from 1.87 p.u. to 1.12 p.u. in response to the arc resistance and the fault distance for the overhead power line with ACSR 70 and ACSR 95 conductors. The overvoltage magnitude decreases by $40 \%$ with an increase in the arc resistance. The maximum magnitude of the phase voltages on the undamaged phases during single phase-to-ground fault reaches up to $43 \mathrm{kV}$. The maximum voltage on the neutral does not exceed $17 \mathrm{kV}$ throughout a single phase-to-ground fault.

\section{Conclusion}

When the power transformer neutral is grounded through a resistor, the overvoltage measured for the undamaged phases approaches magnitudes up to 1.9 p.u. for the tested lines. The highest overvoltage 
magnitude during a single phase-to-ground fault is measured when the fault is at the very beginning of the power line.

The overvoltage have lower magnitudes as is the case with the neutral grounded through resistor when compared to the case with insulated or compensated neutral.

The duration of the transient overvoltage on the undamaged phases at a single phase-to-ground fault with neutral grounded through a resistance is up to $0.02 \mathrm{~s}$.

\section{References}

Etarski, S.I. (1994). Electrical part of power plants. Sofia, Technology.

Shabad, M. A. (2002). Protection against single-phase short circuits to earth in 6-35 kV networks. Sank Petersburg.

Feldman, M. L. (2001). On the issue of neutral grounding methods. International Scientific and Technical Conference, Issue 1, St. Petersburg, p. 66-68.

Shalin, A. (2005). Earth faults in power lines 6-35 kV. Features of occurrence and protection devices. Electrical Engineering News, 1 (31).

Karafeizov, Ts., Grchki, N., Spendzarov, B. (2003). Grounding the star center of a medium voltage system through water resistance. - Energy Forum 2003, Varna, 175-177.

Mehmed-Hamza, M., Vasileva, M., Filipov, A., Yordanova, Y. (2007). Some considerations for the choice of the work regime of the neutral of the power transformer of the electrical power networks medium voltage. IV International Scientific Symposium ELEKTROENERGETIKA 2007, Stara Lesna, Slovak Republic, 167-169

Mehmed-Hamza, M., Vasileva, M., Yordanova, Y. (2009) Coordination of the operation of the relay protection and surge protective devices in electrical power networks medium volt-age $20 \mathrm{kV} \mathrm{J}$. Electr. Eng., 60 (3), 170-172. Google Scholar

Ministry of Energy. (2015). Ordinance № 3 Regarding the construction of electrical switchyards, switchgears and power lines. Retrieved from http://www.gli.government.bg/page.php?c=34\&page $=8$. (in Bulgarian)

Ministry of Energy. (2015). Ordinance № 16-116 for the technical operation of energy equipment. Retrieved from http://www.gli.government.bg/page.php?c=34\&page=8. (in Bulgarian)

Mehmed-Hamza, M., Vasileva, M. (2009). "Using of Matlab Simulink for Education in higt voltage technics and relay protection". ICEST 2009, Veliko Tarnovo, ICEST 2009, 481-482. Google Scholar

БДС ЕN IЕС 60071:2019 Insulation coordination - Part 1: Definitions, principles and rules 